\title{
A study of thin-walled ZL105A casting manufactured by vacuum differential pressure casting
}

\author{
Zhan Shuai $^{1, a}$, Song Jingtao ${ }^{2, b}$,Ding Minghui ${ }^{1, c}$, Jin Guo ${ }^{1, d}$ and Liu Honghui ${ }^{2, e}$ \\ ${ }^{1}$ College of Material Science and Chemical Engineering, Harbin Engineering University, Harbin \\ 150001, PR China \\ ${ }^{2}$ Aviation Industry of China Harbin Dongan Engine (Group) Corporation LTD, Harbin 150069, PR \\ China \\ azhanshuai2012@163.com, binuyasha100@163.com, \\ cding197392@163.com, jinguo@hrbeu.edu.cn, ${ }^{\mathrm{e}} 670217424 @ q q . c o m$
}

\begin{abstract}
Keywords: thin-walled, aluminum alloy, shell casting, vacuum differential pressure, rain type gating system, chill, simulation, process parameters

Abstract. The casting with more than 70\% thin-walled parts and minimum wall thickness of $2 \mathrm{~mm}$ was manufactured by vacuum differential pressure casting (VDPC). The shower gating system was used to ensure smooth filling of melt. The top risers were replaced by chills and the positions of the chills were optimized to eliminate defects in hot spot place. The rational assembling of gating system and chill ensure the progressive solidification of the casting. Moreover, the optimal process parameters were determined as follows: vacuum degree $0 \mathrm{MPa}$, filling pressure $0.1 \mathrm{MPa}$, filling velocity $3.5 \mathrm{~cm} / \mathrm{s}$, rising pressure velocity $0.02 \mathrm{MPa} / \mathrm{s}$, dwell pressure $0.15 \mathrm{MPa}$ and pressure holding time $7 \mathrm{~min}$. The simulation results indicated that the optimized gating system and process parameters could ensure complete filling and progressive solidification of the thin-walled casting. The X-ray and mechanical performances results showed that the complicated and precise aluminum alloy casting could be manufactured by using optimal gating system and casting process parameters.
\end{abstract}

\section{Introduction}

There is a great demand for thin-walled $\mathrm{Al}$ alloy castings with excellent performances in aviation, shipping and automobile industries in recent years. The $\mathrm{Al}$ alloys with high strength and toughness are required to manufacture the castings used in these industries. Al-Si series alloys are found to be good and increasingly used in manufacturing the castings with excellent performances ${ }^{[1-2]}$. However, casting method and process have restricted their application in producing thin-walled castings. For now, thin-walled castings are still difficult to form by using gravity casting ${ }^{[3]}$. The counter-gravity processes such as low pressure die casting (LPDC) and vacuum differential pressure casting (VDPC)

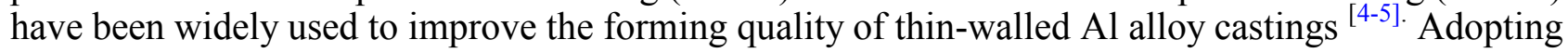
VDPC, the density and strength of castings can be improve highly by placing a mold in a negative pressure field and filling molten metal under controlled pressure ${ }^{[6-7]}$. Yan Q.S et al investigated the effect of holding pressure on microstructure of $\mathrm{Al}$ alloy casting manufactured by VDPC. The results indicated that finer grain and denser microstructure formed at the higher holding pressure ${ }^{[8] \text {. }}$

With the development of industrial, complex Al alloy castings containing more revolution surface, internal oil circuit and thin-walled cavity become urgently needed. To our knowledge, there are few reports on manufacturing castings whose thin-walled portions account for more than $70 \%$ and minimum wall thickness is less than $2 \mathrm{~mm}$. So, further studies on casting method and process are still necessary in order to successfully manufacture such castings. In the paper, we try to use VDPC method to manufacture this kind of thin-walled shell casting and process parameters of filling and solidification are optimized. This paper focuses on designing gating system which is suitable for such complicated thin-walled ZL105A alloy casting and appropriate gating system parameters are designed to control smooth flow state of the liquid metal. The study results of this paper can provide valuable references to the manufacturing of these kinds of similar castings. 


\section{Experimental procedures}

\section{The structure characteristics of the casting and casting material}

Three-dimensional models of the casting with complex internal oil circuit were shown in Fig. 1. Its size is about $186 \mathrm{~mm} \times 164 \mathrm{~mm} \times 182 \mathrm{~mm}$ and the thin-wall parts account for $70 \%$ of all surfaces. The minimum wall thickness is less than $2 \mathrm{~mm}$ in the position of revolved surface. The obvious variation in thickness could be seen in Fig. 1(A) and (B) and the thickness change ratio is 1:14. Internal oil circuit distribution was shown in picture Fig. 1 (C) and (D) and its size is small.

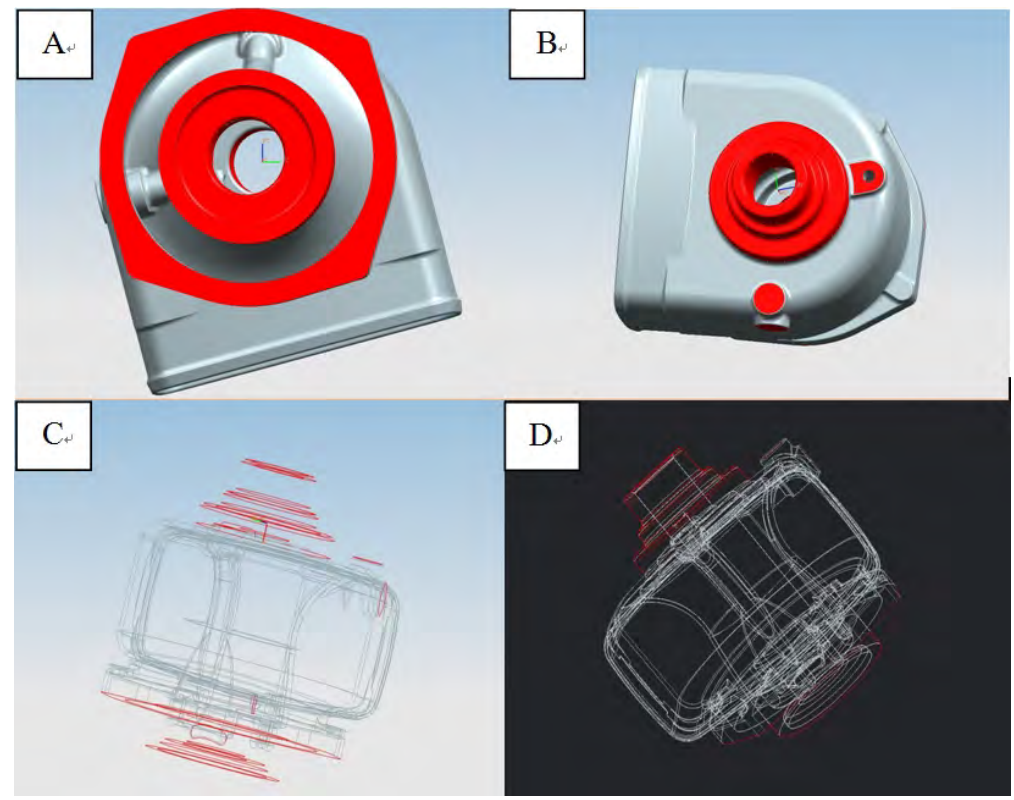

Fig.1. The structures and internal oil distribution state of shell casting: (A) and (B) outward appearance of the casting; (C) and (D) internal oil distribution state of the casting

ZL105A was used as casting material and its chemical component was shown in table 1. It could be found that $\mathrm{Si}$ is added into the alloy as main element. All alloy elements are favorable for improving comprehensive mechanics performance of ZL105A such as tensile strength, hardness and toughness. ZL105A features wide solidification temperature range and more shrinkage defects would form in the casting when the feeding is not timely. VDPC method was selected to produce such castings with excellent quality.

Table 1.-The chemical component and mechanics performance of ZL105A

\begin{tabular}{cccccccc}
\hline \multirow{2}{*}{ Material } & \multicolumn{3}{c}{ Adding elements (\%) } & \multicolumn{4}{c}{ Mechanical properties (sand mould) } \\
\cline { 2 - 7 } & $\mathrm{Si}$ & $\mathrm{Cu}$ & $\mathrm{Mg}$ & Else & $\begin{array}{c}\text { Strength } \\
(\mathrm{MPa})\end{array}$ & $\begin{array}{c}\text { Elongation } \\
(\%)\end{array}$ & $\begin{array}{c}\text { hardness } \\
(\mathrm{HBS})\end{array}$ \\
\hline ZL105A & $4.5 \sim 5.5$ & $1.0 \sim 1.5$ & $0.35 \sim 0.55$ & $\leq 0.5$ & $\geq 270$ & $\geq 5$ & $\geq 85$ \\
\hline
\end{tabular}

\section{Casting pressure parameters design}

All $\mathrm{m}$ VDPC process includes depressurization, metal lifting and filling, pressure rising, dwell pressure, vacuum cooling and pressure releasing. The vacuum degree is the key factor of influencing casting quality in the casting process ${ }^{[9]}$. The higher vacuum degree results in lower back pressure in the mold. The lower back pressure decreases the resistance of the filling process ${ }^{[10-11]}$, which is beneficial to the filling of molten metal. The quality of the casting can be improved by selecting an appropriate vacuum degree. The minimum allowed value of vacuum degree was decided by VDPC equipment and it was identified as $0 \mathrm{MPa}$. The pressure parameter was shown in table 2 .

Table 2.- The pressure parameter

\begin{tabular}{ccccc}
\hline $\begin{array}{c}\text { Filling pressure } \\
(\mathrm{MPa})\end{array}$ & $\begin{array}{c}\text { Filling velocity } \\
(\mathrm{cm} / \mathrm{s})\end{array}$ & $\begin{array}{c}\text { Rising pressure } \\
\text { velocity }(\mathrm{MPa} / \mathrm{s})\end{array}$ & $\begin{array}{c}\text { Dwell pressure } \\
(\mathrm{MPa})\end{array}$ & $\begin{array}{c}\text { Keeping pressure } \\
\text { time }(\mathrm{s})\end{array}$ \\
\hline $0 \sim 0.1$ & 3.5 & 0.02 & 0.15 & 420 \\
\hline
\end{tabular}




\section{Optimal design of gating system}

\section{Gating system type}

The wall thickness of the casting varies greatly and maximum thickness ratio is $1: 14$. Fig. 2 (A) and (B) showed that two bottom risers were added as a transition to eliminate the effect of wall thickness variation, which ensured smooth filling of the casting. The bottom risers changed the thickness ratio from $\delta_{\min }: \delta_{\max }=1: 14$ to $\delta_{\min }: \delta_{\text {riser }}: \delta_{\max }=1: 5: 14$. For complex thin-wall castings, adding of the bottom risers is special significant. For one thing, the decrease of wall thickness variation gradient conduces to control the filling sequence, which results in a stable filling. For another, by using the bottom risers, there are enough liquid metal for feeding during casting solidification. The bottom risers were seen as a part of shell casting where casting solidification terminates and casting defects form commonly. It is difficult to set the chill and gating system for small thin-wall casting. The bottom risers increase setting space of the chill and the design of gating system becomes more reasonable.

The bottom shower gating system was shown in Fig. 2 (C) and (D). By using the bottom shower gating system, liquid metal can distribute smoothly into the ingates, which result in uniform temperature distribution on the surface of liquid metal and elimination of local overheating of the casting. The cold shut and misrun can be prevented effectively for casting by using the gating system with a small filling resistance and short flow route.

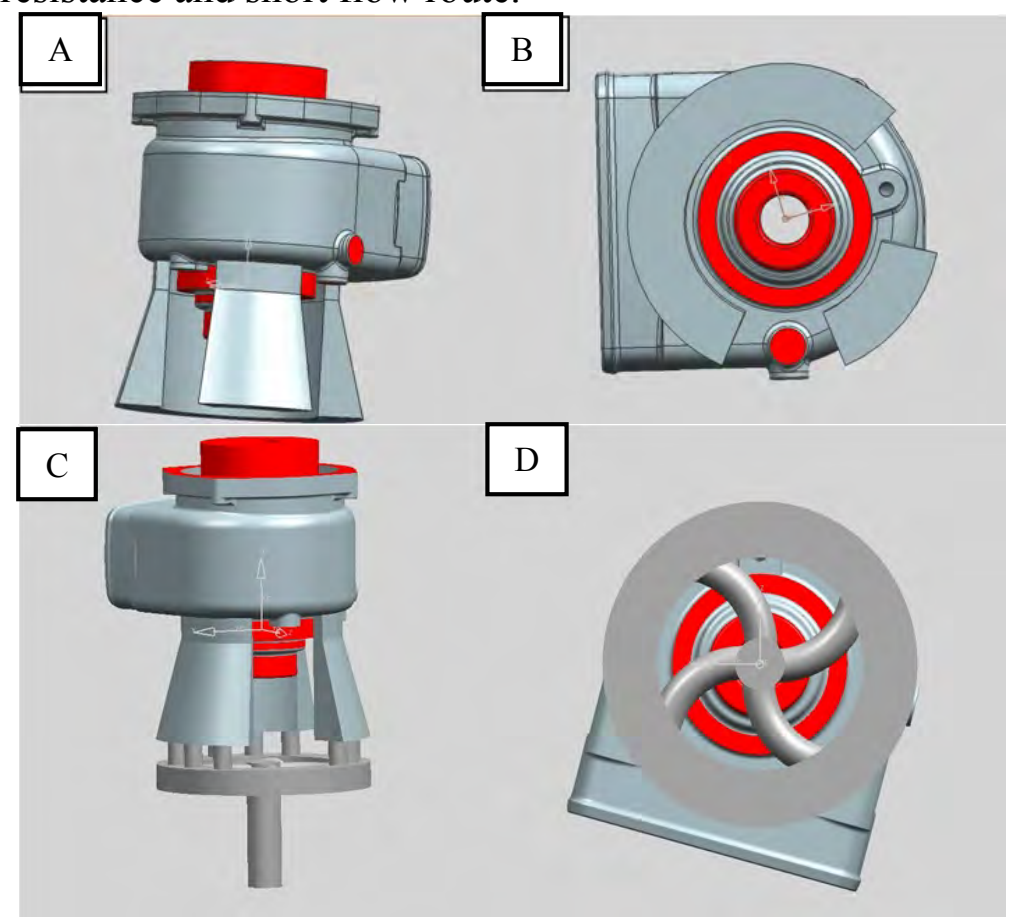

Fig. 2 The bottom riser and shower gating system: (A) front view of the riser; (B) bottom view of the riser (C) front view of the

Ingate design gating system; (D) bottom view of the gating system

The distribution of ingate was shown in Fig. 3. The sectional area of all ingates could be calculated according to the formula (1):

$$
\sum F_{l}=\frac{G}{0.31 \mu t \sqrt{H_{p}}}
$$

$\sum F_{I}$ - Total ingates sectional area $\left(\mathrm{cm}^{2}\right) ; G$-Total filling weight of the casting $(\mathrm{kg}) ; \mu$-Discharge coefficient; t-Filling time (s); $H_{P}$-Average pressure head.

Combining with three-dimensional models of the casting, total weight of the casting is about $6 \mathrm{~kg}$. $\mu$ is 0.48 for the dry sand mold with small filling resistance and filling time is $1 \mathrm{~s} . H_{P}$ is $28 \mathrm{~cm}$ in the bottom shower gating system. The total sectional area of the ingates was calculated by formula (1) and $\sum F_{I}$ is $7.62 \mathrm{~cm}^{2}$. Eleven cylindrical ingates with radius of $5 \mathrm{~mm}$ were set according to shape characteristics of feeding head. 


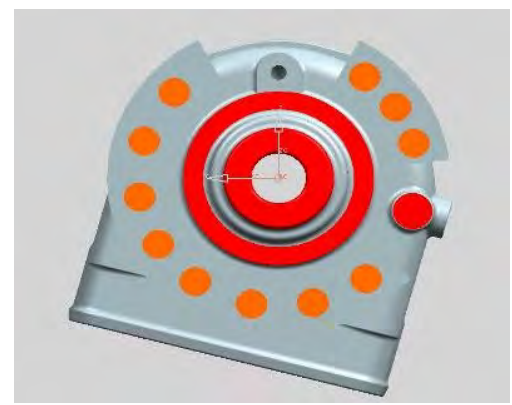

Fig. 3 Ingates position

Cross gate and sprue design

The sectional area proportion of filling gates can be set as $\mathrm{F}_{\mathrm{I}}: \mathrm{F}_{\mathrm{C}}: \mathrm{F}_{\mathrm{S}}=1: 1.4: 1.2$ for small thin-wall $\mathrm{Al}$ alloy casting with complex cavity. $\mathrm{F}_{\mathrm{C}}$ and $\mathrm{F}_{\mathrm{S}}$ are the sectional area of cross gate and sprue respectively. According to $F_{I}$ value of $7.62 \mathrm{~cm}^{2}, F_{S}$ and $F_{C}$ were $9.14 \mathrm{~cm}^{2}$ and $10.67 \mathrm{~cm}^{2}$ respectively. Fig. 4 (A) and (B) showed bottom part of the gating system where riser tube with the radius of $1.7 \mathrm{~cm}$ was used as sprue. Fig. 4 (C) and (D) showed cross gate including ring and $\mathrm{X}$ shape portion. The section sizes of ring and $X$ shape part were shown in Fig. 4(C) and Fig. 4(D). The metal filled smoothly and slag can be put off effectively by applying the gating system.

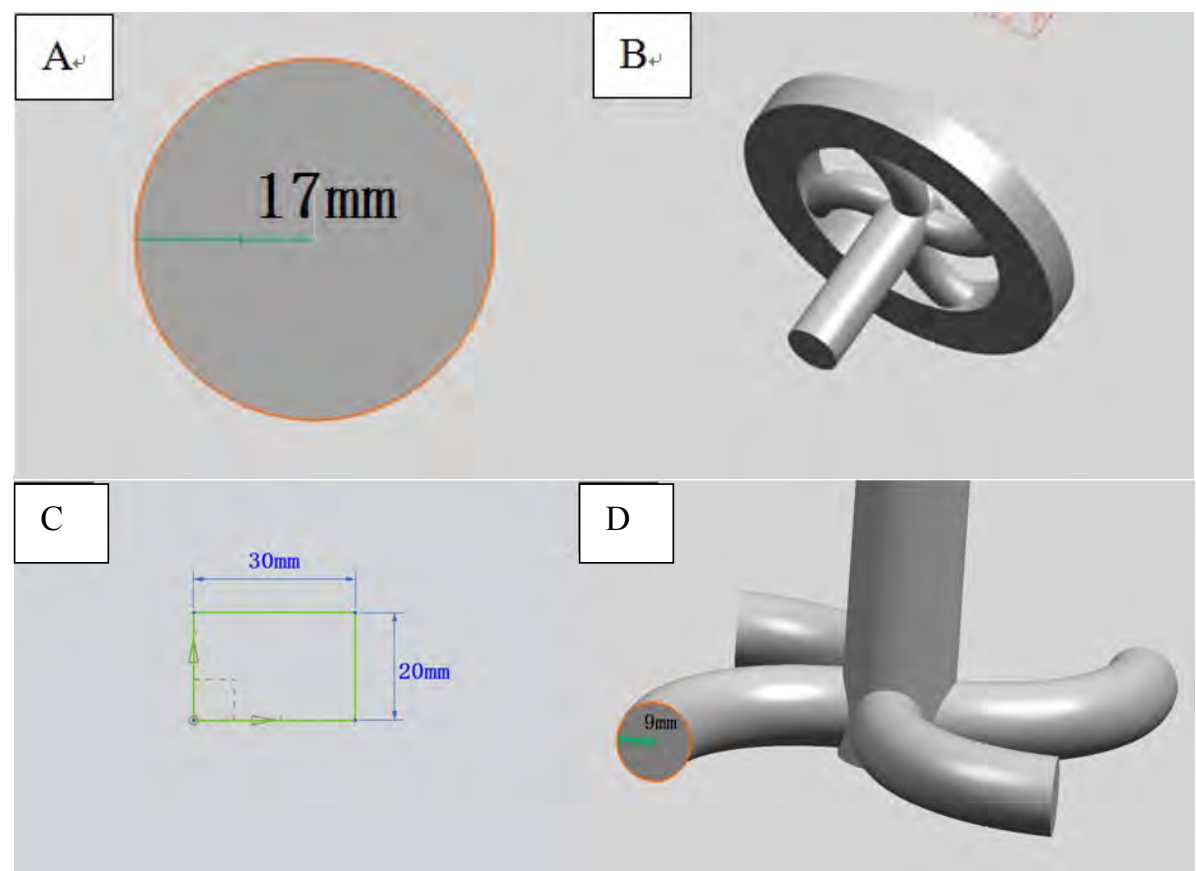

Fig. 4 the size and morphology of the riser tube and cross gate section: (A) the size of the riser tube; (B) the morphology of the riser tube $(C)$ the section size of ring gate; (D) the section size of $\mathrm{X}$ shape gate

\section{Optimal design of the chills}

Progressive solidification process is the key to produce casting with good quality, especially for the castings with thin-wall revolution structure and large wall thickness variation. The top of the casting features big thickness and small geometrical shape variation and solidification rate is slower at the position than thin-wall position. The defects such as shrinkage and porosity form at the hot spot easily and so the top risers were replaced by chill to promote solidification rate of thick wall parts and thus sequence solidification from top to bottom form. The blue part is chill and the rest part is the casting, as shown in Fig.5. In the paper, 40mm thick H13 steel was selected as the chill material and it features good thermal conductivity, big heat capacity and good chilling effect. 


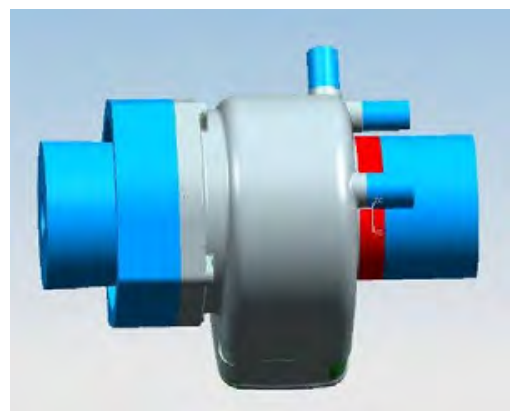

Fig. 5 Distribution of the chills

\section{Results and discussion}

\section{The simulation result discussion}

Initial condition set

Simulation parameters are set as follows. The casting material is ZL105A and chill material is H13 steel. Resin bonded sand is selected to prepare sand mold. The solidus and liquidus temperatures are $510-668^{\circ} \mathrm{C}$ and filling temperature is $720^{\circ} \mathrm{C}$. The sand mold preheating is $50^{\circ} \mathrm{C}$. The interfacial heat transfer coefficient between molten $\mathrm{Al}$ and sand mold is $500 \mathrm{~W} / \mathrm{m}^{2} \cdot \mathrm{K}$ and the heat transfer coefficient is $1000 \mathrm{~W} / \mathrm{m}^{2} \cdot \mathrm{K}$ at the interface between molten $\mathrm{Al}$ and chill.

The filling and solidification state analysis

Filling process of the casting is shown in Fig. 8. It can be observed from Fig.6 (A) that the jet phenomenon takes place at the beginning of filling. Fig.6 (B) shows that surface turbulence has occurred at the position of bottom riser. However, Fig.6 (C) (D) (E) and (F) show that flow fluctuation vanishes and molten metal fills sand mold completely in a laminar flow state when liquid metal pours into mold cavity. The filling time is relatively long for thin wall position of the casting where exist many complex oil channels, as shown in Fig. 6(C) and (D). The fast filling speed can result in casting defects and they can be eliminated by selecting a large bottom riser as a buffer to ensure smooth filling of molten metal.

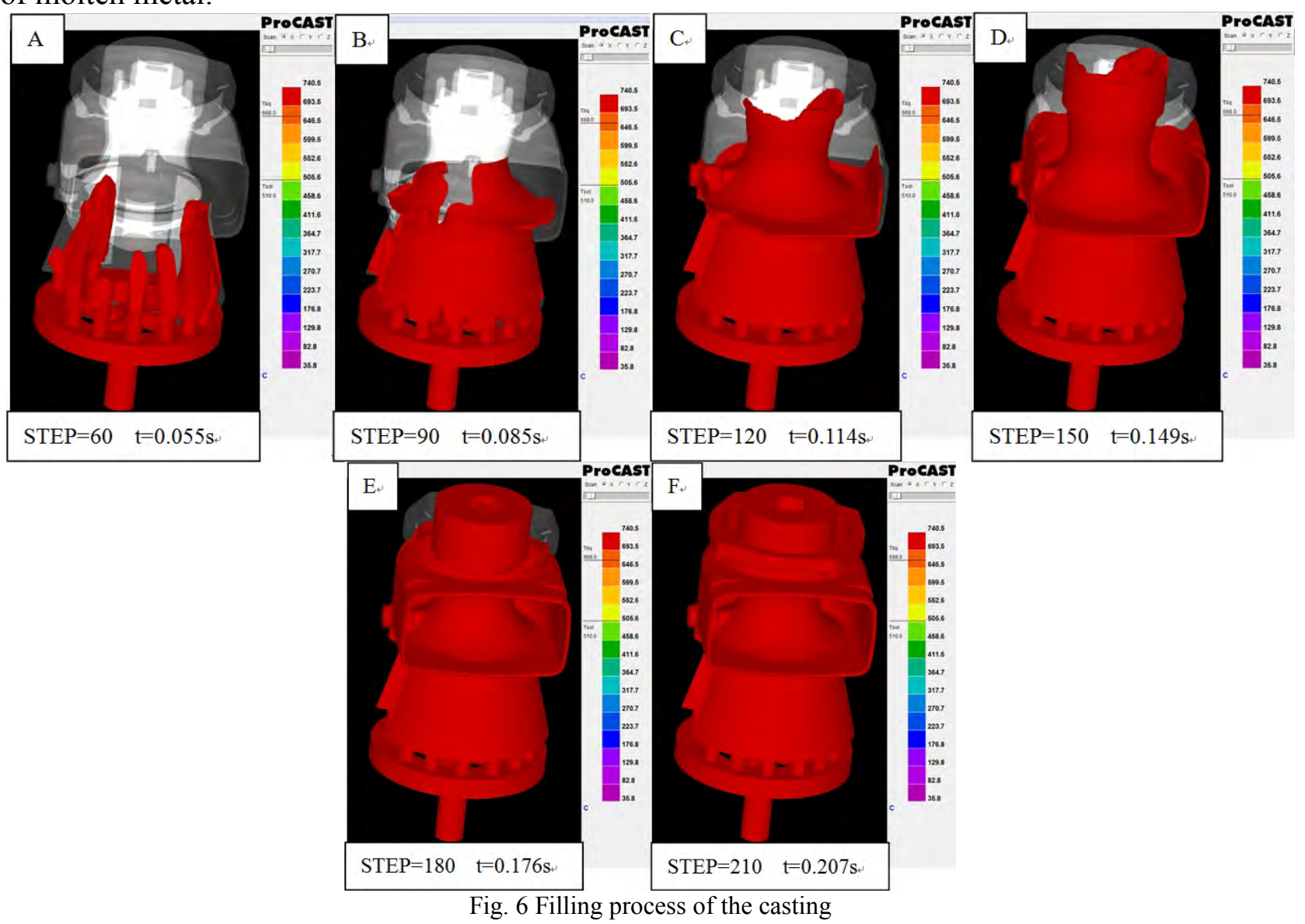


Solidification process simulation result is shown in Fig. 7. It can be seen that solidification speed is fast from the start and the casting temperature has almost dropped below $500^{\circ} \mathrm{C}$ within 21 seconds. Subsequently the solidification speed becomes slow. As shown in Fig. 7(A) and (B), as result of applying bottom riser and chill optimized, a feeding channel forms successfully at position 1. Fig. 7(C) shows that solidification firstly takes place at the position of the chill. It can be seen from Fig. 7(D), (E) and $(\mathrm{F})$, solidification from top to bottom of the casting has formed, which improves the quality of casting.
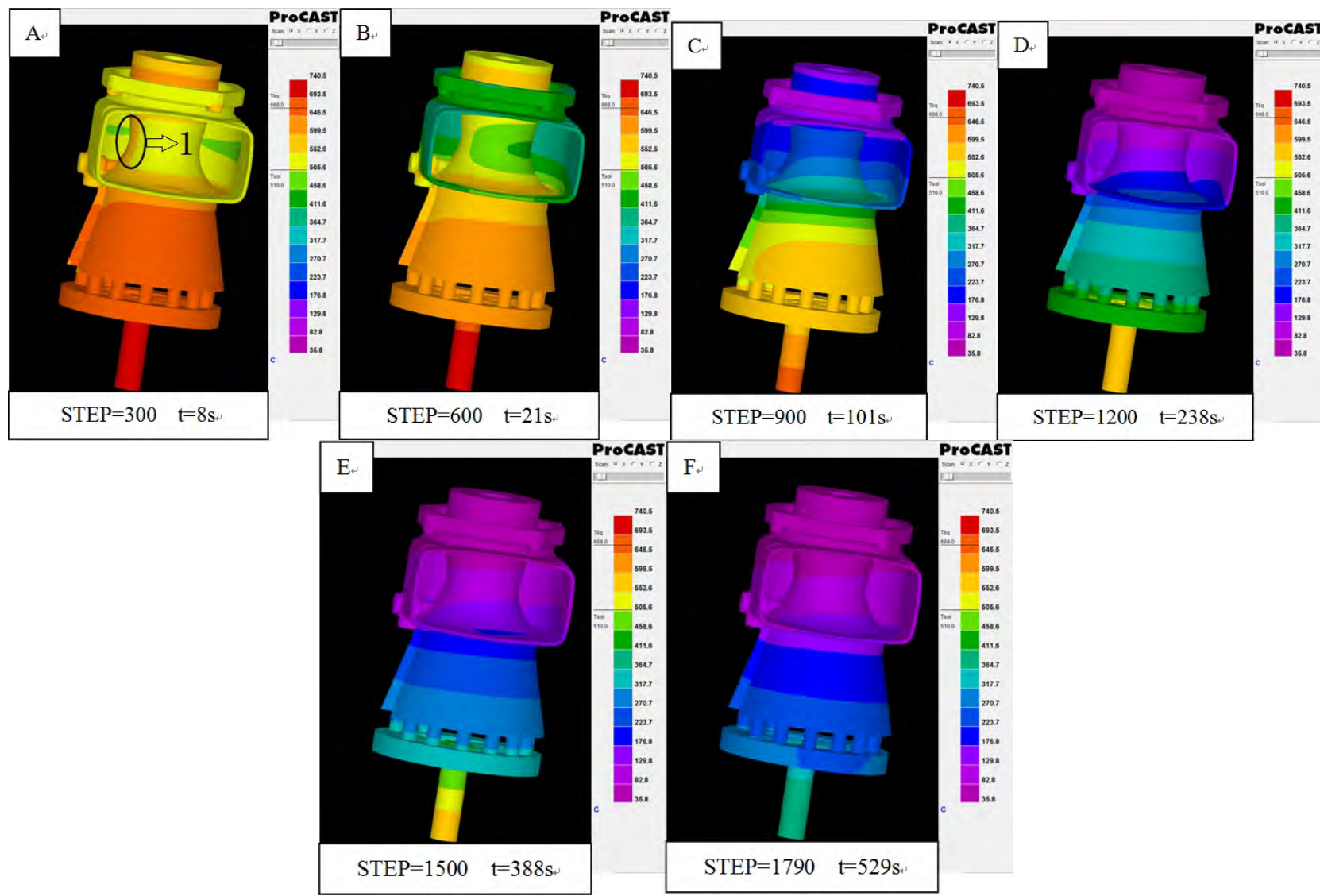

$\mathrm{STEP}=1200 \quad \mathrm{t}=238 \mathrm{~s}$

Fig. 7 Solidification process of the casting

\section{Defect analysis}

Fig. 8 shows simulation result of the shrinkage cavity defects and pink area represents position and size of the shrinkage cavity. It can be seen that there are a few of small shrinkage cavities which concentrate in upper thick parts of the shell casting. Since shrinkage cavities locate in the range of machining allowance, the quality of casting is not affected. It can be concluded from the analysis above that thin-wall casting with defects-free can be realized by optimizing process and rationally assembling riser and chill to ensure the directional solidification and effective feeding of melt.

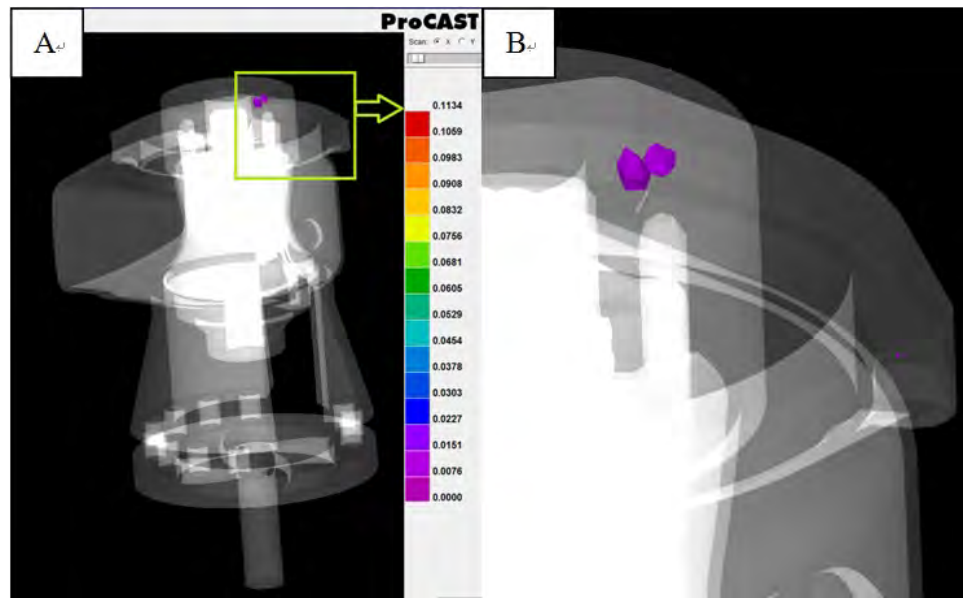

Fig. 8 Shrinkage position and size: (A) complete picture; (B) picture of partial enlargement 


\section{The casting quality detect}

In the paper, thin-walled shell casting is a component on aircraft engine for controlling fuel flow and good mechanical performance requirements are necessary for it. The heat treatment of the casting is $\mathrm{T} 6$ condition and its tensile strength must be more than $294 \mathrm{MPa}$ in this state. In addition, the percentage reduction of area and elongation must be all above 3\% and Brinell hardness must be greater than 95. As Table 3 shows, the inner quality of casting should be up to relevant People's Republic of China aviation standards.

\begin{tabular}{ccc}
\multicolumn{2}{c}{ Table 3.-X-ray detection standards and acceptance quality level } \\
\hline Defects & Standards & Acceptable quality level \\
\hline Circular pinholes & HB6578-92 & 3 \\
Elongated pinholes & HB5395 & 2 \\
Spongy shrinkage & HB5396 & 2 \\
Dispersed shrinkage & HB5397 & 2 \\
Slag inclusion & HB/Z72-1998 & 2 \\
\hline
\end{tabular}

The surface and inner quality

As shown in Fig. 9, the structure of the shell casting manufactured by vacuum differential pressure casting (VDPC) is complete and visual test shows that no obvious defect is found on the surface of the casting.

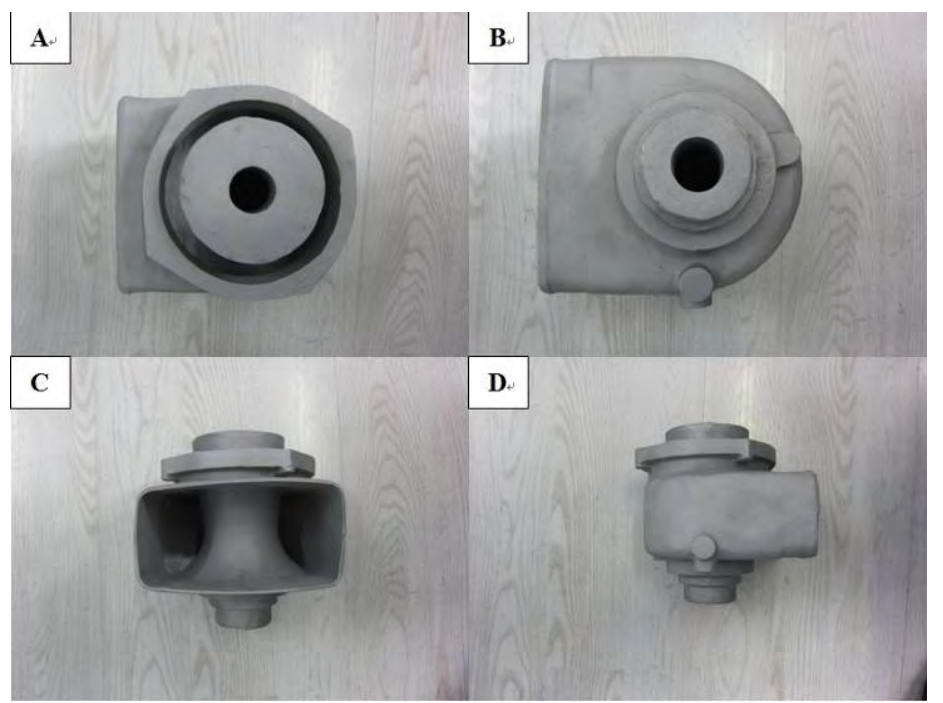

Fig. 9 The pictures of shell casting: (A) top view of the casting; (B) bottom view of the casting; (C) thin-wall area of the casting;

(D) side view of the casting

X-ray detection technique is used to observe inner defects of the casting. X-ray detection images of the shell casting are shown in Fig. 10. It can be observed from Fig. 10 that there are not cold shut, sand inclusion and shrinkage cavity defects in the casting and inner cavity of the casting forms completely. The casting can be used as a component of aviation engine according to People's Republic of China aviation standards HB5395, HB5396, HB5397, HB6578-92 and HB/Z72-1998.

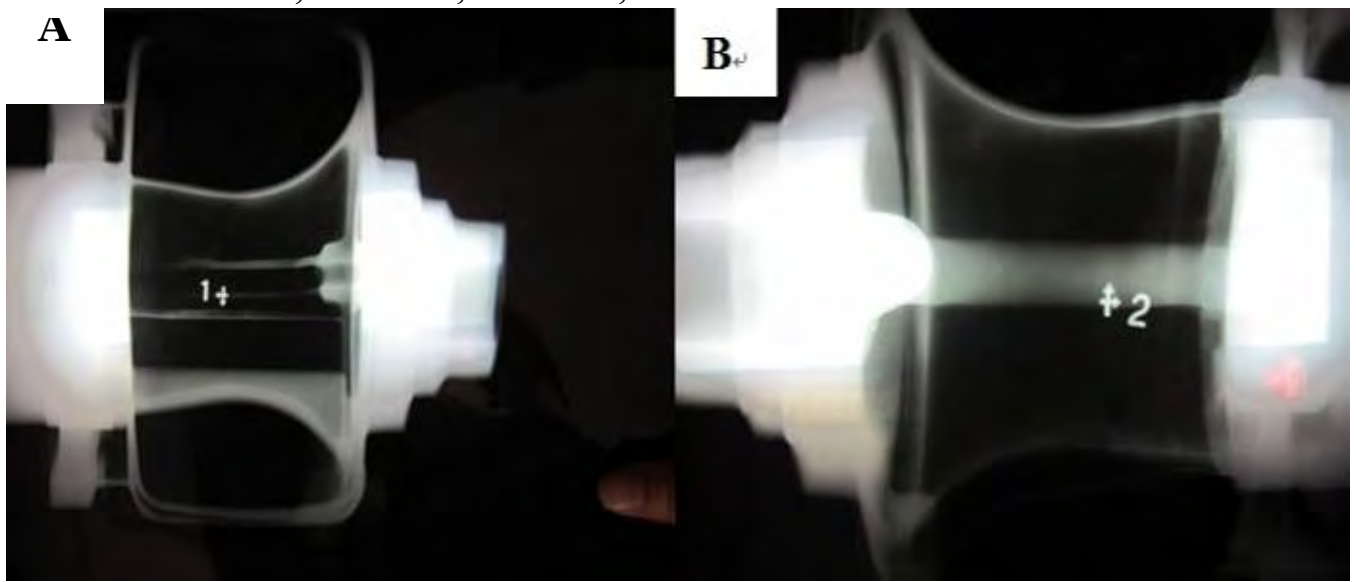

Fig. 10 X-ray detection images: (A) the outline of the casting; (B) a large version of (A) 
The evaluation of mechanical property

Three tensile test bars were machined according to People's Republic of China GB/T 228-2002. The tensile test was performed using an Instron tension machine at room temperature and constant cross-head speed is $1 \mathrm{~mm} / \mathrm{min}$. The results are listed in Table 4 . It can be seen that the comprehensive mechanics performances of the casting meet the technical requirements.

\begin{tabular}{cccc}
\multicolumn{4}{c}{ Table 4.- The comprehensive mechanics performances } \\
\hline$\sigma_{b}(\mathrm{MPa})$ & $\sigma_{0.2}(\mathrm{MPa})$ & Elongation $(\%)$ & Section shrinkage rate (\%) \\
\hline $360.7 \pm 1.9$ & $283.3 \pm 0.6$ & $4.5 \pm 0.014$ & $3.5 \pm 0.038$ \\
\hline
\end{tabular}

The fracture morphology was shown in Fig. 11 and the fracture mode is ductile fracture. A large number of deep dimples and tear ridges can be observed on the fracture surface which favours to improve strength and ductility of the casting.

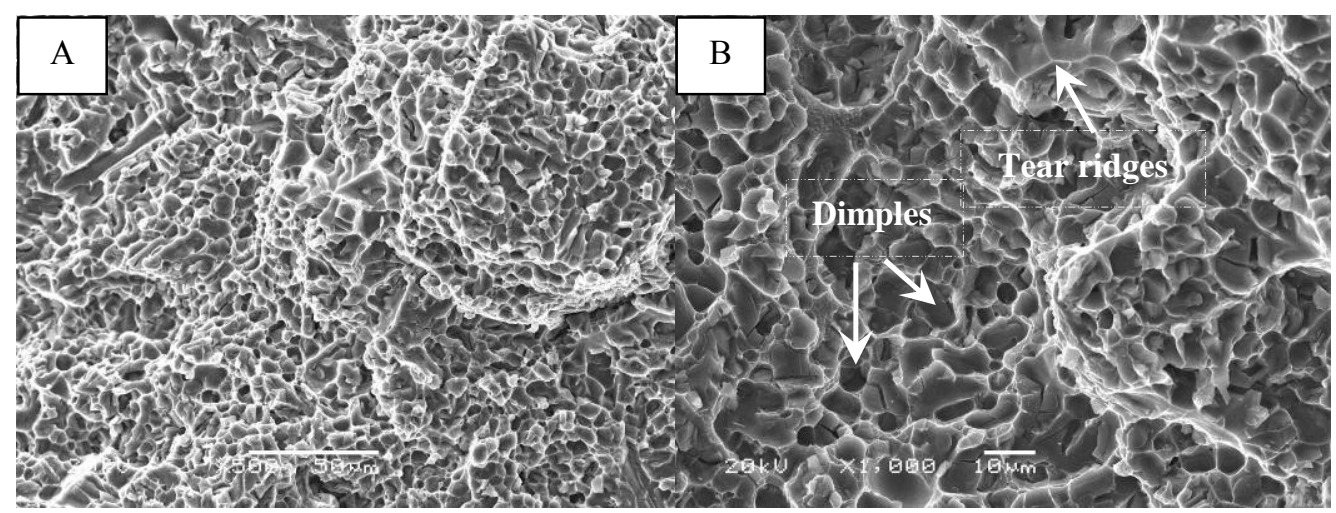

Fig. 11 Tensile fracture graphs of the samples: (A) 500×; (B) $1000 \times$

The Brinell hardness was measured by digital hardness tester and the Brinell hardness value is about 147.2 HBS according to the average of ten measurements. The result shows that the hardness of the casting is far higher than 95 HBS and meets the requirements of aircraft engine castings.

\section{Conclusions}

In the paper, we manufactured the thin-walled Al alloy casting with great thickness variation by vacuum differential pressure casting (VDPC) method which appear to upper and lower thicker and center thinner. The bottom risers connected with thin wall part of the casting, which decrease the thickness ratio from $\delta_{\min }: \delta_{\max }=1: 14$ to $\delta_{\min }: \delta_{\text {riser }}: \delta_{\max }=1: 5: 14$. Combined with using the bottom shower gating system, the smooth filling process of melt was ensured. The top riser was replaced by the chill and it combined with shower gating system make progressive solidification of the casting. In addition, the chills were set at the hot spot position, which eliminate shrinkage cavity and shrinkage porosity, especially shrinkage and porosity of thickness mutation position. Optimal gating system and casting process parameters of manufacturing the thin-walled casting were set up, which give a basis for manufacturing of other casting like it.

\section{Acknowledgements}

This work was financially supported by National Basic Research Program of China (973 Program) (No. 2011CB013404), the Application Technology Research and Development Projects of Heilongjiang Province (GC13A103), Science and Technology Research Projects of Harbin City (2014AB4BG061), National Natural Science Foundation of China (No. 51275105, 51375106), Fundamental Research Funds for the Central Universities (No. HEUCF). 


\section{Reference}

[1] Saad G, Fayek S A, Fawzy A, Soliman H N, et al. Deformation characteristics of Al-4043 alloy, Materials Science and Engineering A, 2010, 527: 904-910.

[2] Dorum C, Laukli H I, Hopperstad O S, et al. Structural behaviour of Al-Si die-castings Experiments and numerical simulations, European Journal of Mechanics A-Solids, 2009, 486: 219-222.

[3] Zhang L Q and Wang R J. An intelligent system for low-pressure die-cast process parameters optimization, International Journal of Advanced Manufacturing Technology, 2013, 65: 517-524.

[4] Jiang W M, Fan Z T, Liu D J, et al. Influence of gas flowrate on filling ability and internal quality of A356 aluminum alloy castings fabricated using the expendable pattern shell casting with vacuum and low pressure, International Journal of Advanced Manufacturing Technology, 2013, 67: 2459-2468.

[5] Lerner V S, and Lerner Y S. Solidification modeling of continuous casting process, Journal of Materials Engineering and Performance, 2005, 14: 258-262.

[6] Littleton H E and Druschitz A P. Vacuum Assisted Filling of Lost Foam Castings, Proc. 114th int. Cong. Orlando, March 2010, Paper 118, 493-501.

[7] Xu N N, Zhuang Z Y, Zhang H G. Analysis of Vacuum Casting Pressure Time and Its Influence on Casting Quality, Proc. Conf. on 'Asia Simulation Conference/International Conference on System Simulation and Scientific Computing', Shanghai, PEOPLES R CHINA, October 2012, Paper 323, 76-83.

[8] Yan Q S, Yu H, Xu Z F, et al. Effect of holding pressure on the microstructure of vacuum counter-pressure casting aluminum alloy', Journal of alloys and Compounds, 2010, 501: 352-357.

[9] Kumar S H, Kumar P D, Shan H S. Effect of process parameters on impact strength of Al-7\% Si alloy castings produced by VAEPC process, International Journal of Advanced Manufacturing Technology, 2008, 38: 586-593.

[10] Duan J L, Maijer D, Cockcroft S, et al. Development of a 3D Filling Model of Low-Pressure Die-Cast Aluminum Alloy Wheels, Metallurgical and Materials Transactions A, 2013, 44A: 5304-5315.

[11] Lee S M, Seo P K, Kang C G. Effect of injection velocity on structure part characteristic in AZ50 die casting process with high vacuum system, Journal Materials Science and Technology, 2008, 24: 75-79. 